\title{
Notas sobre II Encontro Nacional de Educação Patrimonial - Iphan \\ Ouro Preto-MG, 17 a 21 de julho de 2011 (1)
}

José Hermes Martins Pereira *

Há tempos que as discussões sobre Educação Patrimonial deixaram de ser exclusivas dos técnicos envolvidos com a salvaguarda do patrimônio cultural. Não menos importante é a constatação de que comunidades tradicionais, educadores sociais, empresas e outros setores da sociedade civil têm reconhecido o potencial emancipador das ações educativas com o foco no patrimônio, seja ele material ou imaterial, institucionalizado ou não.

Experiências recentes no campo, como as Casas do Patrimônio (2), assim como consensos e inquietudes provenientes da natureza multidisciplinar das ações em Educação Patrimonial, trazem à tona um arco de questões ligadas à gestão e avaliação, cooperação e participação social, perspectivas teóricas e especificidade da formação para atuar na área.

Estimulado por uma agenda tão extensa de questões, e com o objetivo principal de discutir estratégias para a implantação de uma política nacional de Educação Patrimonial, foi promovido pelo Instituto do Patrimônio Histórico e Artístico Nacional (Iphan) o II Encontro Nacional de Educação Patrimonial, que contou com quatro dias intensos de atividades, distribuídas entre as Mesas (3) e os Grupos de Trabalho (GTs), (4) que foram organizados de forma a cobrir, a partir de seus temas específicos, as principais demandas para a elaboração de uma política nacional de Educação Patrimonial.

Nesse sentido, não por acaso a primeira Mesa realizada, A educação patrimonial e as políticas públicas para o patrimônio cultural, proporcionou aos participantes um balanço das estratégias e ações desenvolvidas pelo Iphan no âmbito da educação patrimonial, desde 2004, quando foi criada a Coordenação Geral de Promoção do Patrimônio Cultural (Cogeprom), com uma gerência de Educação e Projetos. Márcia Rollemberg, diretora do Departamento de Articulação e Fomento do Iphan destacou em sua fala a sequência de iniciativas colocadas em prática pelo órgão desde então, pontuando a importância da realização do I Encontro de Educação Patrimonial, em 
2005, e a implementação do projeto das Casas do Patrimônio, a partir de 2008, em constante avaliação. (5)

$\mathrm{Na}$ mesma mesa, a presença de Leandro Fialho, da Secretaria de Educação Continuada, Alfabetização e Diversidade do Ministério da Educação, foi de fundamental importância para incitar os participantes do Encontro na reflexão sobre a distância ainda existente entre as políticas de educação e de cultura. Apesar das novas diretrizes do MEC para a educação escolar basearem-se na ampliação de tempos, espaços e oportunidades educativas, e do consequente reconhecimento das cidades como territórios educativos e educadores, não havia, ao menos até aquele momento, aproximação efetiva entre as duas esferas de atuação para o fomento às ações de educação patrimonial - ainda muito circunscritas a iniciativas pessoais e bastante dispersas entre si.

Há exemplos dessa constatação espalhados por todo o país, como demonstraram as comunicações apresentadas nas três mesas de discussão. Kátia Bogéa, da regional do Iphan no Maranhão, relatou a experiência bem sucedida do órgão em Alcântara (6) com a implantação do projeto Patrimônio contado: Alcântara, educação e cultura. $\mathrm{O}$ projeto intentava inicialmente a elaboração de material didático e a criação de uma disciplina de educação patrimonial no currículo do Ensino Fundamental II, para sua aplicação. Em função das dificuldades encontradas, a solução foi a produção de livros paradidáticos, a serem adotados na disciplina de Língua Portuguesa. Elaborado a partir da realização de um inventário de referências culturais com a população local, o material foi produzido gradualmente e hoje conta com uma coleção de seis livros, quatro deles utilizados do $6^{\circ}$ ao $9^{\circ}$ ano, mais dois livros do professor. A capacitação de professores, aliás, é outra via de desdobramento do projeto, em avaliação e monitoramento constantes.

Assim como a iniciativa maranhense, a quase totalidade das ações apresentadas são ligadas a superintendências regionais e/ou Casas do Patrimônio do Iphan, caso dos programas apresentados por Salma Saadi e desenvolvidos na cidade de Goiás Velho/GO (7); de Gisely Cesconetto, em Laguna/SC (8); e de Rosiane Lima Verde, na Casa do Patrimônio Chapada do Araripe/CE (9), ou ainda a parceria bem sucedida entre o Iphan e a Prefeitura Municipal de Iguape (10), comunicada pelo 
secretário de cultura Carlos Alberto Pereira Junior. As exceções foram as comunicações de Antonio Carlos de Moura Sartini, que trouxe ao evento a experiência do setor educativo do Museu da Língua Portuguesa, em São Paulo/SP, e de Simone Scifoni, do departamento do Geografia da FFLCH-USP, que apresentou o projeto em andamento nessa Universidade intitulado "Educação Patrimonial na USP" (11), desenvolvido em parceria com o Centro de Preservação Cultural (CPC-USP) e que tem como objetivo o mapeamento e a reflexão em torno das ações de educação patrimonial desenvolvidas no Estado de São Paulo.

Baseando-se na tabulação das informações já obtidas, Simone ponderou sobre os desafios de ordem teórica e prática enfrentados em diferentes iniciativas, apontando o descompasso existente entre os discursos e as condições reais de execução dos projetos. Ao apontar a dispersão e mesmo a insuficiência dos referenciais téoricos na área, a geógrafa reacendeu o debate sobre a influência do Guia básico de educação patrimonial (1999) e do Manual de atividades práticas de educação patrimonial (2007), publicações oficiais tidas ao mesmo tempo como fundadoras e como responsáveis pela dogmatização das práticas nesse campo.

A questão do dogmatismo metodológico, que permeou boa parte dos debates, também ganhou espaço na fala do museólogo Mário Chagas (Ibram-MinC), segundo o qual "forjou-se" um marco inicial para a Educação Patrimonial nos anos 1990, atitude que teria desconsiderado todo um histórico de reflexões e de ações levadas a cabo por educadores e por teóricos com as mais variadas orientações preocupados com o patrimônio como expressão humana.

Tendo em vista o entusiasmo dos participantes (que segundo o Iphan foram mais de 250, provenientes de todos os estados do Brasil); as queixas diversas - falta de recursos e de profissionais capacitados, descontinuidade das ações -; e as diferentes visões sobre a Educação Patrimonial, perceptíveis nas mesas de discussão, pode-se dizer que o evento reflete bem o status atual da Educação Patrimonial.

Como que a traduzir esse momento de valorização da Educação Patrimonial não apenas no âmbito da educação e da cultura, mas também como promotora de 
cidadania e desenvolvimento local, os eixos dos Grupos de Trabalho (GTs) trouxeram à tona temas como marcos legais, gestão e avaliação (GT1); espaços educativos e cooperação (GT2); sustentabilidade e participação social (GT3); perspectivas teóricas em educação, patrimônio cultural e memória: um diálogo interdisciplinar (GT4).

A análise dos temas postos em discussão, ainda que rápida e baseada em nossa impressão geral do evento, deixa entrever as imbricações entre as questões práticas da Educação Patrimonial enquanto política pública e questões de ordem teórica e metodológica inerentes ao trato com o patrimônio cultural. De um lado estão as práticas e as tentativas de normatização de um campo que exige cada vez mais a compatibilização entre os discursos de profissionais e as necessidades de grupos sociais diversos. De outro lado, há um consenso em torno da especificidade do tema, caracterizado pela interdisciplinaridade, dentro e fora do campo educacional.

Em nossa participação no GT4, foi possível perceber como as perspectivas teóricas no campo ainda se ressentem de uma indefinição, decorrente seja da ascendência dos conceitos próprios à área do patrimônio cultural - tanto em sua face material quanto imaterial -, seja da resistência à ideia de que as ações se desenvolvem enquanto práticas educativas e, portanto, prescindem de discussões metodológicas vinculadas à pedagogia. Nesse sentido, a dispersão, ou mesmo a insuficiência da bibliografia disponível poderia ser atribuída à fragilidade de uma produção em grande parte caracterizada por relatos isolados de iniciativas circunscritas temporal e espacialmente, em detrimento da necessária discussão teórica e conceitual.

Diante de tal impasse, algumas saídas possíveis foram encaminhadas pelo Grupo como diretrizes para o documento final do evento, a saber:

Diretriz 1: Criar mecanismos que permitam a discussão e o aprofundamento dos referenciais teórico-metodológicos, bem como a sistematização e a difusão da produção bibliográfica e da diversidade de experiências e inovações na área, considerando a troca entre os diferentes campos do conhecimento tradicional e acadêmico, em sua interdisciplinaridade.

$(\ldots)$ 
Diretriz 2: Fomentar e promover programas e projetos de formação interdisciplinar em diferentes espaços de educação formal e informal.

(...)

Diretriz 3: Propor e garantir estratégias e mecanismos que promovam o intercâmbio/articulação entre os diversos atores envolvidos na construção das ações e na implementação das políticas de EP. (12)

Os grifos na citação acima chamam a atenção para aspectos amplamente defendidos pelos integrantes do GT e vinculam-se, sobretudo, às necessidades de produção e difusão de conhecimentos na área e de valorização dos saberes tradicionais e dos responsáveis pelas ações de Educação Patrimonial. Surgida como uma demanda metodológica, a difusão das experiências e inovações na área tem como premissa a constatação de que a constituição de um arcabouço teórico e conceitual da Educação Patrimonial passa obrigatoriamente pela reflexão acerca da historicidade, dos conteúdos disciplinares e dos componentes ideológicos inerentes às suas práticas.

$\mathrm{Na}$ plenária final do evento, foi aprovado por votação um documento contendo 11 propostas de diretrizes e 30 de ações elencadas pelos quatro grupos de discussão e trabalho. O documento foi disponibilizado para consulta prévia no sítio do Iphan, para que fossem enviadas novas contribuições à sua construção, que se espera, seja feita de forma coletiva e democrática. Conforme informações também disponíveis no sítio oficial, todas as contribuições serão disponibilizadas pelo blog da Casa do Patrimônio de Ouro Preto (http://programasentidosurbanos.blogspot.com), e serão compiladas e sistematizadas pela equipe da Coordenação de Educação Patrimonial do Iphan, com auxílio dos redatores do Encontro. O documento final será publicado no site do Iphan e dos parceiros da rede Casas do Patrimônio.

\section{Notas}

(1) O autor participou do Encontro como representante do Centro de Preservação Cultural (CPC-USP), órgão da Pró-Reitoria de Cultura e Extensão que desenvolve, desde 2004, ações de educação patrimonial em seu imóvel sede, a Casa de Dona Yayá.

(2) Conforme definição do Instituto do Patrimônio Histórico e Artístico Nacional (Iphan): "As Casas do Patrimônio constituem-se, essencialmente, em um projeto pedagógico e de educação patrimonial. É o primeiro passo para transformar as sedes das representações regionais, os escritórios técnicos do Iphan, e instituições da sociedade civil em pólos de referência local e regional para qualificar e atender a população residente, estudantes, 
professores, turistas em uma perspectiva de diálogo e reflexão, no sentido de participarem da construção coletiva dessa nova postura institucional. Trata-se de conferir transparência e ampliar os mecanismos de gestão da preservação do patrimônio cultural, apoiando-se principalmente em ações educacionais, em parceria com escolas, instituições educativas formais e informais e demais segmentos sociais e econômicos". Além da definição, os objetivos das Casas e algumas ações por elas já organizadas podem ser conferidos em: $<$ http://portal.iphan.gov.br/portal/montarPaginaSecao.do?id=15489\&retorno=paginalphan>.

(3) Mesa 1: A Educação patrimonial e as políticas públicas para o patrimônio cultural; Mesa 2: A educação patrimonial: desenvolvimento e cidadania; Mesa 3: Casa do Patrimônio: informação, educação e comunicação.

(4) GT 1: Educação patrimonial, marcos legais, gestão e avaliação; GT 2: Educação patrimonial, espaços educativos e cooperação; GT 3: Educação patrimonial, sustentabilidade e participação social; GT 4: Perspectivas teóricas em educação, patrimônio cultural e memória: um diálogo interdisciplinar.

(5) Com essa finalidade seria realizado, em 2009, o $1^{\circ}$ Seminário de avaliação das Casas de Patrimônio, cujas discussões foram sistematizadas na Carta de Nova Olinda.

(6) Tombada desde 1948, Alcântara teve 45\% de seu território estabelecido como área de segurança nacional, em função de sua base aérea. O fato levou à expulsão da população, incluindo comunidades quilombolas dessa área, situação que foi considerada no estabelecimento das ações de educação patrimonial.

(7) Em Goiás Velho foram desenvolvidas atividades educativas em obras de restauro, com recursos oriundos das próprias obras. Podem ser citados os projetos Tocando a obra, com apresentações musicais em igreja em reforma, e Canteiro aberto, que recebia a visitação de cerca de 3 mil alunos por mês. $O$ trabalhou chegou a atingir também 23 assentamentos rurais, numa parceria com a Pastoral da terra e o MST.

(8) Em Laguna, além da realização de oficinas de formação para professores e profissionais envolvidos direta ou indiretamente com o turismo (guias, guardas municipais, taxistas, comerciantes, etc.), foi implantado o programa Cinema Falado, que mais tarde daria origem ao Cine Iphan - Cineclube Laguna.

(9) A Casa do Patrimônio de Nova Olinda, no Ceará, teve início com o Memorial do Homem Kariri, idealizado pela comunidade local em casa erguida no século XVIII no mesmo local da antiga aldeia Kariú Kariri. Oficializado como Fundação Casa Grande, o memorial ainda hoje tem sua gestão realizada pela comunidade local, organizada sob a forma de cooperativa, e constitui-se como importante vetor de geração de renda, por meio da prestação de serviços ligados ao turismo.

(10) Entre as iniciativas, destacam-se o fomento ao debate democrático das questões que envolvem o patrimônio arquitetônico da cidade, assim como iniciativas de valorização do cotidiano e da cultura local como meio de fortalecer os vínculos de pertencimento e cidadania.

(11) Projeto integrante do programa "Aprender com cultura e extensão", da Pró-Reitoria de Cultura e Extensão Universitária. Além do mapeamento das ações de educação patrimonial no Estado de São Paulo, o projeto possui outra frente, intitulada "Conceituação e práticas na Casa de Dona Yayá. Desenvolvida pelo CPC-USP, essa frente tem como intuito a reflexão sobre as ações ali desenvolvidas e a proposição de novas atividades que promovam uma reaproximação do órgão com escolas de seu entorno. 
(12) Redação original das diretrizes encaminhadas pelo GT4 à plenária final. Grifos do autor.

\section{Referências bibliográficas}

GRUNBERG, Evelina. Manual de atividades práticas de educação patrimonial. Brasília/DF: Iphan, 2007.

HORTA, Maria de Lourdes Parreira; GRUNBERG, Evelina; MONTEIRO, Adriane Queiroz. Guia básico de educação patrimonial. Brasília: Iphan/Museu Imperial, 1999.

\section{Crédito}

* Historiador (FFLCH-USP), mestre em Arquitetura e Urbanismo (FAUUSP), é Especialista em Pesquisa/Apoio de Museu do CPC-USP. 